This is the author's Post-print version (final draft post-refereeing as accepted for publication by the journal). The definitive, peer-reviewed and edited version of this article is published as: van Ham M., Hooimeijer P. and Mulder C.H. (2001) Urban form and job access: Disparate realities in the Randstad. Journal of Economic and Social Geography (TESG) 92, 231-246. http://dx.doi.org/10.1111/1467-9663.00152

\title{
URBAN FORM AND JOB ACCESS: DISPARATE REALITIES IN THE RANDSTAD
}

\author{
MAARTEN VAN HAM, PIETER HOOIMEIJER \& CLARA H. MULDER
}

Urban Research Centre Utrecht - NETHUR, Faculty of Geographical Sciences, Utrecht
University, PO Box 80.115, 3508 TC Utrecht, The Netherlands. E-mail:
m.vanham@geog.uu.nl

\begin{abstract}
Deconcentration of employment is the driving force behind the rise of the complex urban forms of the polycentric city and the polynucleated metropolis. It is often assumed that the deconcentration process improves job access for average and highly skilled workers, allowing them to move to peripheral residential locations and triggering a new round of urban sprawl. It is also hypothesised that access to suitable job opportunities is withheld from low-skilled workers living in inner-city neighbourhoods as a result of the deconcentration of low-skilled employment beyond their commuting tolerance. In this contribution we illustrate how network-oriented GIS provides an instrument to enable the evaluation of the job access of residential locations at varying levels of commuting tolerance and for various types of employment. Application of this instrument to the metropolitan area of the Randstad shows that suburban locations in between major employment centres are clearly superior for households with highly skilled workers, making urban sprawl towards residential locations outside the Randstad unlikely. It is also shown that for poorly skilled workers with limited commuting tolerance the central city is still the best place to live.
\end{abstract}

Key words: job access, commuting tolerance, polycentric urban structures, network-oriented GIS

\section{INTRODUCTION}

The spatial mismatch between where workers live and where jobs are located is a cause of both wasteful commuting, creating inefficiencies, and of underemployment among those with limited commuting tolerance, creating inequities. The deconcentration of employment-the dominant process in the rise of polycentric urban forms-changes this spatial mismatch, bringing work closer to suburban residential locations and taking it farther away from inner-city neighbourhoods. New questions arise, such as whether these suburban locations now provide better job access leading to shorter commutes and whether poor workers in the inner-city become deprived of job opportunities. The answers to these questions would seem self-evidently to be in the affirmative; however, inspection reveals that reality is somewhat more complex.

The issue of varying commuting tolerance is prominent in the literature on urban land use. The classic land use model (Alonso, 1964) is constructed on the monocentric city in which all jobs are assumed to be located in the CBD. A worker's choice of a residential location is made on the basis of a trade-off between housing quality and commuting costs. Workers with lower incomes and therefore limited commuting tolerance tend to occupy the high density, low quality urban housing while those 
with higher incomes and a greater commuting tolerance move to low density, high quality housing in the suburbs.

The deconcentration of employment has led to polycentric urban structures with multiple centres of employment and services and dispersed patterns of residential locations. It has repeatedly been claimed (Hall, 1984; Gordon et al., 1987; Batten, 1995) that polycentric structures are more efficient than monocentric structures, because deconcentration reduces the gap between job locations and housing developments. The implicit assumption in this argument is that while employment is dynamic, residential locations remain fixed. Clark and Kuijpers (1994) question this assumption. In their view, the deconcentration of employment increases the scale of suburbanization. Sites for residential development at a greater distance from the city centre come within the range of the deconcentrated employment centres. The development of these sites over a wider area causes urban sprawl and commuters' increased automobile dependence, contributing to congestion.

This image of the expanding metropolis created by Clark and Kuijpers is based on an implicit assumption. Even though both residence and employment are dynamic, the authors assume the dominance of the workplace in the search for a residential location; people choose a dwelling within commuting range of their place of work. This assumption is increasingly becoming invalid. In an era when many dual-earner household have to combine more than one workplace with one place of residence and where people change jobs more often, the choice of residence depends less on one job in a fixed location than on the number of jobs (including the present ones) within reach of the residence. Rather than assume that within the radius of a given employment centre the residential location is immaterial, the location should be evaluated in terms of access to multiple centres. In polycentric urban structures residential locations will vary in job access depending on the distances to employment nodes and the transportation structures linking the residence to these nodes.

The first objective of this contribution is to describe an instrument to measure the job access of residential locations. Job access is the number of employment opportunities that can be reached within a fixed commuting time from the residence via the transportation network. The question addressed is: which (urban or suburban) residential locations are favourable in terms of access to multiple jobs, given the level of commuting tolerance of the households involved.

The issue of underemployment among those with limited commuting tolerance is incorporated in the literature on labour economics. Here the implicit assumption is one of residence place dominance. Job search is assumed to start at home and commuting enters the analyses in the form of monetary or time expense. According to Fisher and Nijkamp (1987), up to the late 1980s labour economists have neglected the spatial dimension of labour markets. In the more recent debate on the spatial mismatch for low-skilled workers, two aspects are pervasive; commuting tolerance and segmentation of the labour market (see Preston \& McLafferty, 1999). The first aspect, limited commuting tolerance, creates a spatial barrier to job access (Holzer et al., 1994). Commuting tolerance might be a problem not only for low skilled workers (because of the monetary costs of commuting relative to the wage level), but also for part-time employees (because of the time-costs relative to the number of working hours) (Madden \& White, 1980). According to Hanson and Pratt (1992): "For the majority of the workforce, the set of job opportunities actually available, or seriously considered, is highly spatially constrained." It cannot be assumed that people can access any job within a regional labour market defined on the basis of average commuting tolerance. The second aspect is the segmentation of the labour market. The labour market consists of separate functional labour markets characterized by a specific demand for labour (Batenburg \& De Witte, 1996). The segmentation is of particular relevance for workers with highly specialized human capital and for workers lacking the proper qualifications to enter jobs requiring higher skills. For this group, the relevant market is not determined by the total number of jobs within commuting tolerance, but by the number of opportunities for which they qualify.

The second objective of the paper is to describe the application of the instrument that measures job access in evaluating the effect of variation in commuting tolerance and of the spatial distribution of job opportunities in functional submarkets. The questions addressed are: which residential locations are more favourable to those with limited commuting tolerance in general; to those whose job search is constrained by a lack of higher skills in particular; to those with a high commuting tolerance, but specialized human capital. 
The remainder of this paper is organized in five parts. Section two presents a theoretical framework within which the job access of individuals from the residence can be understood. Section three deals with variation in the job access of residential areas as a result of their location relative to the geographical distribution of job opportunities at two geographical levels: the single urban region; the metropolitan region of the Randstad. There, the commuter sheds of several urban regions overlap, facilitating the evaluation of the effects of variation in urban form. Section four describes the instrument to measure job access and the data. Section five presents the empirical results in the form of a series of map images; the final section puts forward a conclusion.

\section{COMMUTING AND MIGRATION TOLERANCE}

Job access depends on the geographical distribution of job opportunities and on the individual spatial flexibility in reaching these opportunities. Spatial flexibility can be split into commuting tolerance (the possibility of covering the distance between home and work) and migration tolerance (the possibility of adjusting the residential location) (Hooimeijer, 1996). We consider first commuting tolerance, then migration tolerance, moving to the geographical distribution of jobs in the next section.

In the neo-classical labour market approach, the concept of commuting tolerance takes the form of the monetary cost of commuting. Jobs are within reach as long as commuting costs do not exceed a certain percentage of the gross wage rate. Following this line of reasoning, Phelps (1970) pictured the economy as a group of labour market islands between which moves are costly. The cost of commuting deters workers on one island from accepting jobs located on other islands. Hägerstrand (1970) recognized that, besides monetary costs, commuting time is also an important constraint on spatial behaviour. From a fixed residential location, the journey to and from work is only possible when this occurs within the daily activity space of an individual. This constraint can seriously restrict people's access to suitable jobs (cf. Hanson \& Pratt, 1992).

By including skills in the definition of a worker's job search area, Simpson (1992) added an important principle to the theoretical framework within which the job access of individuals can be understood. According to the human capital theory (Becker, 1962), workers invest in productivity enhancing skills and strive to maximize the utility of this accumulated human capital. The stock of human capital people accumulate during their lifetime has three main components. The first is general human capital, commonly acquired through the education system and enhancing productivity equally in all firms. The second component is sector-specific human capital (Simpson, 1992). This human capital does not enhance productivity equally in all firms, but only in a specific sector of the economy. The third component is the enterprise-specific human capital acquired with tenure (on-the-job training) and, in contrast with general and sector specific human capital, is not transferable across employers. According to the human capital theory, people differ in the level and specialization of human capital. Because the costs of a job change are considerable when a worker with specific human capital moves to a job where these specific skills cannot be utilized, not all jobs are valued equally and only a subset of the total jobs available is suitable.

The skills of workers also have an influence on their spatial flexibility or commuting tolerance. According to Börsch-Supan (1990), skills have a double-edged impact on labour mobility. With increasing level and specialization of human capital, the probability of a job change decreases while at the same time geographic mobility increases. Highly specialized jobs have a lower spatial density so workers with specific skills have to be more flexible spatially. An important aspect of the human capital theory is that human capital accumulates over the life course. In order to obtain a better return on investments in human capital, people need to change jobs several times. They do so especially at the beginning of their labour career (see Topel \& Ward, 1992). This so-called job shopping enables individuals to try out several jobs to determine their comparative advantage, find higher quality job matches and achieve better pay. Especially for higher educated workers at the beginning of their labour career spatial flexibility is a necessity for career advancement. For lowskilled workers this is less the case. The costs of spatial flexibility relative to the potential increase in wage level are too high. Because jobs for low-skilled workers are more evenly spread there is less to 
gain from spatial flexibility. Their labour market flexibility consists of moving into another trade within the same local labour market. While the job mobility of lower-skilled workers is higher, their spatial flexibility is lower.

A generally accepted standard for commuting tolerance is 45 minutes for a single work trip (Wachs \& Taylor, 1993; Van Ommeren, 1996). Research by Van Ommeren (1996) shows that for commutes up to 30-45 minutes, resistance does not increase much with commuting time. When commuting time exceeds 45 minutes however, resistance to commuting increases sharply. A commuting tolerance of 45 minutes is just the average upper limit; however, since people differ markedly in their time-space restrictions, at the individual level large variations in commuting tolerance can be expected.

Until now, there has been little empirical research on differences in commuting tolerance between socio-economic groups. Much more is known about variations in the actual commuting times of workers. Wachs and Taylor (1993) find for the US that almost two thirds of all employees spend less than 35 minutes commuting to work. Similar results can be obtained for the Netherlands. Based on the 1996 Netherlands Labour Force Survey (see CBS, 1997) we found that nearly 50\% of those employed in the Netherlands commute less than 15 minutes per single work trip. More than $80 \%$ commute less than 30 minutes. Fewer than $9 \%$ of the working population commute more than 45 minutes. These findings indicate that indeed only a very small proportion of the working population is prepared to undertake long commutes over 45 minutes.

Many authors have pointed out that women have consistently shorter commuting trips than men do (Madden, 1981; Gordon et al., 1989). According to Hanson and Pratt (1992) this can be explained by the fact that women are faced with severe day-to-day space-time constraints, dictated in part by their domestic workload. The presence of young children in the household particularly restricts the daily activity space of women. The above indicates that the household situation is an important determinant of commuting tolerance.

Commuting tolerance is only one aspect of spatial flexibility; the alternative to long-distance commuting is migration. It has long been established that commuting both complements and substitutes for migration (Termote, 1980). Any change in workplace requires a concurrent decision either to change the residential location and the commuting (complements), or to adhere to the original residential location and change the commute (substitutes).

Over the last few decades commuting tolerance has increased and migration tolerance has decreased as a result of the rise in the share of dual-earner households. Dual-earner households have a lower propensity to a residential move than couples or families with a single breadwinner (Mulder, 1993; Mulder \& Hooimeijer, 1999; Jarvis, 1999). Migration tolerance is lower for dual-earner households, since they have to combine more than one workplace with one residential location. The commuting tolerance of the partners in these households on the other hand is higher, because the household income provides a larger budget for fast modes of transportation. This effect has been exacerbated by the rising educational level of women as this leads to higher gross household wages, enabling the purchase of more efficient means of transportation. This rise in human capital also widens the job search area, triggering geographical mobility.

Lower migration tolerance makes the choice of a residential location more strategic. Locations providing easy access to multiple jobs permit maximum spatial flexibility using commuting as a substitute for migration. Even when people migrate because of an employment transition, the choice of a new residential location will depend not only on the location of the present job, but also on the access to other jobs (for the partner, or for jobs later in life). This strategy, which is perfectly rational at the level of the individual household, shows up as wasteful commuting at the aggregate level.

\section{JOB ACCESS OF RESIDENTIAL AREAS AND THE VARIATION IN URBAN FORM}

The shift in micro-level decision making resulting from decreasing migration tolerance has two important implications for the evaluation by individual households of the job access of residential locations. The first is that households in residential areas with access to numerous jobs migrate less in 
the case of an employment transition. The second is that households that do move find residential areas that provide access to a large number of jobs more favourable. The job access of residential areas depends on the location relative to the geographical distribution of employment opportunities and therefore on the macro-level development of urban form. In the Netherlands we observe a gradual shift from monocentric into polycentric urban structures.

The monocentric urban model is based on the city as a daily urban system with an urban core of employment and a surrounding suburban residential area (Van der Laan et al., 1998). The deconcentration of employment has resulted in the emergence of subcentres and therefore more complex daily urban systems with multi-directed patterns of traffic flow. Increasingly, commuter sheds of individual polycentric cities tend to overlap each other. At a higher spatial level, this development leads to the emergence of large polynucleated metropolitan regions which develop from the integration of several older nodes located relatively close to each other (Van der Laan, 1998). These large urban regions do not contain a primate city and are often perceived as a single functional unit. Examples in Europe are the Rhine-Ruhr metropolitan region in Germany, the Flemish Diamond in Belgium and the Randstad in the Netherlands (Dieleman \& Faludi, 1998).

\section{Figure $1 \quad$ Map of the Netherlands}

The Randstad is a classic example of a polynucleated metropolitan region (figure 1). This complex urban region in the western part of the Netherlands contains the cities of Amsterdam, The Hague, Rotterdam and Utrecht-the four main cities of the Netherlands-and several additional smaller nodes. These cities are located in close proximity to each other and connected by intensive road and rail networks. The Randstad has 7 million inhabitants (almost $45 \%$ of the total population of the Netherlands) and contains a major concentration of jobs (over $50 \%$ of all the jobs in the Netherlands) on $20 \%$ of the territory. The centre of the Randstad is a large open central area, the Green Heart, where agriculture is still the dominant form of land use. This characteristic has led the British planner Gerald Burke (1956) to designate the Randstad Greenheart Metropolis.

In the past 25 years, two major changes have taken place in the Netherlands economy. At the level of individual cities, employment has become suburbanized, moving from the centre to the edge of cities, locating at motorway exits (Hessels, 1992). At the same time, a relative shift has taken place from the Randstad to adjacent areas (Van der Vegt \& Manshanden, 1996). These major changes in the economy have led to a greater dispersal of job opportunities in absolute terms. However, according to Batenburg and De Witte (1992) there are still large regional differences in the Netherlands in the qualitative employment structure (sector and job level).

It is not self-evident how the continuing deconcentration of employment and the rise of polycentric structures will affect job access in various residential areas in the metropolis. Priemus (1998) observed that many residential locations have been developed on the outer edge of the Randstad, whereas employment has mainly developed on the inner flank of the Randstad, between the four largest cities. These uneven spatial developments might be a cause of greatly increased interregional commuting (cf. Atzema \& Schutjens, 1995). This would indicate that the deconcentration of job opportunities does not automatically resolve the spatial mismatch of jobs and housing.

In short, access to jobs from residential areas depends on two macro-level factors. The first is the geographical location relative to the dispersed employment opportunities that have been suburbanized in specific directions. The second is the position of the residential location with respect to the transportation infrastructure, which provides access to centres of employment, particularly to the road infrastructure since new employment centres tend to locate at accessible locations along the motorways.

In evaluating the job access of residential areas, the part played by micro-level factors must also be assessed. The first factor is the commuting tolerance of the workers involved. For those with limited commuting tolerance, job searching will be restricted to a single or limited number of employment concentrations, while those with a wide commuting tolerance may reach several employment centres. The second factor is the level of skill of the workers involved. Those with medium or high skill levels may choose to accept a job requiring less skill, but closer to home. Those with limited skills can only enter jobs for which they meet the requirements. The third factor is the 
sector of the economy in which the worker has specialized. The evaluation of the job access of a residential location will differ for different groups. In combination, these factors lead to job access values that differ substantially between socio-economic groups for a vast number of residential areas.

\section{METHODOLOGY AND DATA}

From the discussion above it can be concluded that an instrument to measure the job access of a residential area for various socio-economic groups has to meet four requirements. The first is the spatial resolution. Both residential and employment locations should be measured at a detailed geographical level to evaluate variation in access to a large number of jobs in dispersed locations, taking into account the variation in commuting tolerance among the population. The second requirement is acknowledgement of the crucial role of the transportation networks linking residences to jobs, in particular the road networks since nearly $90 \%$ of commuters in the Netherlands use private modes of transport (CBS, 1997). The quality of the connection, in terms of the speed on the segments, is decisive in determining the number of jobs that are within reach. The third requirement is that the instrument should be applicable at various spatial scales, measuring the effects of both the deconcentration of employment within a single urban region and also of the overlap of the commuter sheds of individual cities within a wider metropolitan region. The fourth requirement is that the instrument should be generic, that is to say no a priori delimitation of geographical area, functional submarkets, or household groups should be needed.

To meet the first requirement, taking optimal account of individual spatial restrictions, the measurement would have to start from a very low spatial level (cf. Louter, 1997). Four digit postal codes were chosen as the starting point (almost 4000 in the Netherlands). To handle this geographical detail the choice for a geographical information system is obvious. However, few geographical information systems meet the second requirement, that distances should be measured in time spent using transportation infrastructure to get from one point to another. FLOWMAP, a network-oriented GIS extension developed at the Faculty of Geographical Sciences, Utrecht University (see De Jong \& Floor, 1993) meets this requirement. The database includes the full road network, including the average travelling speed on each segment. Algorithms to find the shortest path (measured in time) can be used to calculate the full matrix of travelling times between every postal code area, meeting the third requirement, as both short and long distances are included in the output. These distances can then be weighted on the basis of the total number of jobs, or a subset of jobs that require specific skills within commuting reach of each postal code area.

In order to apply the instrument to measure job access as described above to evaluate the effect of variation in commuting tolerance and the spatial distribution of job opportunities we made two choices. Because we want to answer the question which residential locations are more favourable to workers with different levels of commuting tolerance, the first choice is that we measure job access for three different values of commuting tolerance (15, 30 and 45 minutes one way commuting). These three levels reflect a low, middle and high level of commuting tolerance. The second is that we use absolute measures of the number of jobs within reach instead of applying some correction for the competition for these jobs from other job searchers residing in the same area. We do so, because what we are interested in, is a measure of the total opportunity set, which determines the probability of a suitable job becoming available.

The data on the spatial distribution of jobs in the Netherlands by sector come from a unique dataset: the National Information System on Employment ${ }^{1}$ (LISA). This dataset is a registration of nearly all the establishments in the Netherlands, including government and other non-commercial organizations. An establishment is defined as an individual plant, store, or office; multi-establishment firms have separate listings for each establishment. The data set includes information about total employment per establishment (total number of full time and part time jobs), type of economic activity, and the location of each job site by address. To estimate job access on the basis of the LISA dataset, all establishments are geocoded to a postal code area using work site addresses. The data available was for 1997. 
LISA does not contain information concerning job levels. To obtain this data an alternative source had to be used. We used a pooled sample of the Labour Force Surveys (EBBs) conducted by Statistics Netherlands in 1994, 1995 and 1996. This pooled set of about 300,000 respondents contains information on the work location and job level of all working respondents in almost 600 municipalities. With this information we estimated a distribution of job levels for all 4-digit postal code areas (using the 5 job levels of Statistics Netherlands).

Job access was estimated in a two step process. In the first step, the full matrix of travelling times between postal code areas was calculated. The travelling time between two locations depends on the travel mode used. For the purpose of this article, travelling times by car over the road network ${ }^{2}$ were used. This choice is justified, because more than $55 \%$ of workers in the Netherlands commute by car (CBS, 1997). For workers who travel by bicycle or on foot this choice results in an overestimation of their job access. The road network used includes data on average driving speeds per road segment. With the software package FLOWMAP (De Jong \& Floor, 1993) travelling times by car where calculated from the centroid of each postal code area to all other postal code areas over the road network. Unfortunately it was not feasible to include congestion. In the second step, for each postal code $i$ FLOWMAP identified all other postal codes $j$ whose centroids were within 15, 30, or 45 minutes travelling time by car over the road network (a proximity count) and added up all the jobs (full time and part time) within this area. This procedure was followed for all the almost 4000 postal codes in the Netherlands, which resulted in a unique value of job access for each postal code area.

\section{JOB ACCESS IN MAPS}

In table 1, the number of jobs within reach is shown for a selection of postal code areas (see the numbers in map 1 for their geographical location). For cities a postal code in the city centre was taken. The postal codes in the table have been selected to reflect the influence of variation in urban form in combination with variation in commuting tolerance on job access.

The first row of the table gives the average number of jobs that can be reached in the Netherlands. This row shows the overall effect of commuting tolerance on job access. At a tolerance of 15 minutes, an average over postal codes of 73,000 jobs are within reach. A tolerance of 30 minutes raises this number by a factor of 5 to 361,000 jobs. At 45 minutes the average number of jobs equals 862,000, twelve times the number at 15 minutes.

The subsequent rows give a first indication of the role of the spatial distribution of employment in job access. Three interesting phenomena appear. The first is, as expected, that the geographical distribution of job opportunities matters. At a tolerance of 15 minutes the number of jobs nearly follows the rank-size rule of the places involved. The highest number of jobs can be reached from Utrecht and Eindhoven (the largest cities in the table). The second is that the effect of the distribution shifts as commuting tolerance increases. The postal code area in the geographical centre of the Green Hart provides a perfect example. At 15 minutes only 6,000 jobs can be accessed, indicating a position at the bottom of the table. At 45 minutes this number has increased to 1.9 million, making this postal code the third in the hierarchy of job access among the listed locations. More generally, rising commuting tolerance has a much larger effect in the polynucleated metropolitan region of the Randstad, where commuter sheds overlap, than in the single urban regions in the more peripheral parts of the country. In the city of Groningen (in the north) a rise from 15 to 45 minutes generates just over three times the number of jobs within reach, while in the city of Utrecht ten times as many jobs come within reach if commuting tolerance is raised from 15 to 45 minutes. The third phenomenon is that the position with respect to the major road infrastructure makes a difference. This is illustrated by comparing Woerden, a small town located on one of the motorways (A12 between The Hague and Utrecht) that cut through the Green Hart with the postal code at the centre of the Green Hart. The geometrical location of the two places hardly differs, but the location of Woerden on the motorway provides more jobs locally and facilitates access to other employment centres along the A12 (at 15 minutes) and connecting motorways (at higher levels of commuting tolerance). 
Table 1 Number of jobs within reach by commuting tolerance (between brackets the multiplication factor compared with job access within 15 minutes)

\begin{tabular}{|l|l|l|l|}
\hline & 15 minutes & 30 minutes & 45 minutes \\
\hline Average job access & 73,000 & $361,000 \quad(5)$ & $862,000 \quad(12)$ \\
\hline & & & \\
\hline 1 Utrecht & 293,000 & $1,081,000 \quad(4)$ & $2,947,000 \quad(10)$ \\
\hline 2 Eindhoven & 206,000 & $470,000 \quad(2)$ & $961,000 \quad(5)$ \\
\hline 3 Amersfoort & 173,000 & $808,000 \quad(5)$ & $1,888,000 \quad(11)$ \\
\hline 4 Almere & 134,000 & $974,000 \quad(7)$ & $1,696,000 \quad(13)$ \\
\hline 5 Groningen & 128,000 & $267,000 \quad(2)$ & $433,000 \quad(3)$ \\
\hline 6 Woerden & 118,000 & $904,000 \quad(8)$ & $2,673,000 \quad(23)$ \\
\hline 7 Nijmegen & 106,000 & $400,000 \quad(4)$ & $874,000 \quad(8)$ \\
\hline 8 Arnhem & 96,000 & $398,000 \quad(4)$ & $1139,000 \quad(12)$ \\
\hline 9 Zwolle & 69,000 & $233,000 \quad(3)$ & $626,000 \quad(9)$ \\
\hline 10 Leeuwarden & 65,000 & $173,000 \quad(3)$ & $323,000 \quad(5)$ \\
\hline 11 Hoogeveen & 28,000 & $134,000 \quad(5)$ & $456,000 \quad(16)$ \\
\hline 12 Centre of green heart & 6,000 & $217,000(36)$ & $1,897,000(316)$ \\
\hline
\end{tabular}

Source: LISA 1997 (in co-operation with VROM)

An overall evaluation of the job access of residential areas in the Netherlands is possible when the job access of all areas is mapped at three levels of commuting tolerance (15, 30, and 45 minutes): figures 2 to 4 show the results. The cutting points in the legend have been based on the average rise in the number of jobs within reach as a result of the change in commuting tolerance (5 times at 30 minutes, 12 times at 45 minutes). If commuting tolerance were the only factor determining job access the maps would be identical. The differences derive from the geometrical location relative to the distribution of employment and the position with respect to the road network.

Job access within 15 minutes (figure 2) shows the most fragmented image. The larger cities and their immediate surroundings pop up as labour market islands. Yet even at 15 minutes the effect of the transportation network shows up in the maps. The Hague in particular shows radiating job access towards the north-east (along the A4 motorway to Amsterdam) and the south-east (along the A13 towards Rotterdam). The transportation network has a double effect on job access. First, the motorways provide rapid access to a wider area. Second, the exits of the motorways have become favourable locations for new employment centres. This can be seen east of the Hague along the A12, in the postal code areas of Zoetermeer. These locations are at the nearest exit from the Hague and have developed as a local employment centre. The cities and part of their surrounding suburbs are favourable locations in terms of access to employment for people who can afford to own and use a car, but have restricted time-budgets. The 15 minutes map also gives an indication of the number of jobs that can be reached by people who go to work by bicycle or on foot, although at a much higher level of commuting tolerance.

Job access at 30 minutes (figure 3) shows a radically different picture. At this level of commuting tolerance the cities lose their competitive advantage in terms of job access. The Randstad clearly shows up as the region with overall high job access, but the best locations are the suburban areas in between the larger employment centres and not the city centres. The major motorways become visible in the pattern of job access. In particular, the A2 from Amsterdam to Eindhoven in the south-east shows up as a major corridor. The degree of fragmentation within the Randstad indicates that the image shows the effect of the overlapping commuter sheds of numerous employment centres. However, within 30 minutes, even at the best location not more than 1.35 million jobs can be reached, close to $40 \%$ of all the jobs in the metropolis. Since $70 \%$ of even the highly skilled male workers commute 30 minutes or less, this map shows a realistic picture of the variation in the numbers of jobs within reach for large segments of the population.

Figure 4 shows that at 45 minutes the Randstad again has the highest values of job access, ranging from 1.2 million jobs (in the worst locations) to nearly 3 million (in the best locations). From most of the postal code areas in the Randstad, workers with a commuting tolerance of 45 minutes can 
access between $60 \%$ and $90 \%$ of all jobs in this part of the country. For them, the Randstad as a whole is close to being a single regional labour market. Combining or changing jobs without having to migrate is easy in this part of the country. Further away from the Randstad, the number of jobs within reach decreases rapidly, even at this level of commuting tolerance.

Figure $2 \quad$ Jobs within reach, 15 minutes

Source: LISA 1997 (in co-operation with VROM)

Figure $3 \quad$ Jobs within reach, 30 minutes

Source: LISA 1997 (in co-operation with VROM)

Figure $4 \quad$ Jobs within reach, 45 minutes

Source: LISA 1997 (in co-operation with VROM)

The conclusion so far is that job access is disparate within the Netherlands as a whole and in the Randstad in particular. For those with a high level of commuting tolerance the Randstad comes close to a single labour market. Moving from the centre of the Randstad to more peripheral areas, the gradient in the number of jobs that can be accessed is very steep. Because for many employees, working in the Randstad and living elsewhere would imply commuting times of well over 45 minutes, urban sprawl towards residential locations outside the Randstad is unlikely. At 30 minutes commuting tolerance-close to the average actual commuting time for better-skilled workers-suburban locations combine good quality housing and attractive residential surroundings with job access superior to that in the cities. For dual-earner households suburban locations provide advantages over urban living in most respects. Urban sprawl is bound to occur within the confines of the Randstad as a whole rather than in the form of an expanding metropolis. For those with the lowest level of commuting tolerance the Randstad does not exist; their labour market is the single urban region and not the metropolis (or parts of the polynuclear metropolis).

Low-skilled workers are constrained in their job search in two ways. The first is the effect of their limited commuting tolerance; the second is their inability to enter jobs requiring more skills. Only a subset of jobs is open to them. Assuming a commuting tolerance of 15 minutes for this group, we reran the analyses for figure 2 , including only the jobs that require elementary or basic skills. The results are displayed in figure 5 for the Randstad.

Figure $5 \quad$ Basic and elementary jobs within reach of 15 minutes in the Randstad Source: LISA 1997, EBB 1994-1996

The results indicate that in general terms only $40 \%$ of all job opportunities are within the reach of this group, with a maximum of 147,000 positions from the best location in the country. Also for this group, the cities and their immediate surroundings show up as the best locations. In particular the largest cities, Amsterdam and Rotterdam, show a high concentration of basic and elementary jobs.

As labour mobility is high among those with low skills (fewer have tenured jobs and many move from one trade to another) the actual number of potential jobs to apply for is crucial for remaining in employment. In terms of numbers of jobs to choose from, the city itself therefore still seems the best place to live for people with limited skills and limited commuting tolerance. A policy aimed at improving access to suburban housing opportunities for these groups would seem to be less efficient, because this would entail their having to move to places where job access was lower. Increasing commuting tolerance to 30 minutes would be more effective since this would, on average, increase job access by a factor 5 .

Not only does the lack of human capital play an important part in job access; so does the degree of specialization. On-the-job training and work experience (sector specific human capital) limit people in their job mobility. As an illustration, job access has been mapped for a sector which requires a high level of sector specific human capital: Advanced Producer Services (APS). The LISA 1997 data set contains about 240,000 jobs in this sector, including jobs in computer services, information 
technology, legal and financial services, architecture, and engineering. To map job access in this sector, 30 minutes of commuting tolerance was used.

Figure $6 \quad J o b s$ within reach, 30 minutes: Advanced Producer Services

Source: LISA 1997 (in co-operation with VROM)

The results reveal the tremendous effect of the level of specialization. Only 4\% of all job opportunities are within the reach of this group. At 30 minutes commuting tolerance, the best location in the Randstad gives access to slightly more than 85,000 jobs in the sector (compared with 1.35 million if all jobs were equally relevant). Compared with the overall map at 30 minutes, the more peripheral areas of the Randstad (north and west of Amsterdam, south of Rotterdam) are less favourable and the best locations are even more concentrated in the corridors along the major motorways (the A2, Amsterdam to Eindhoven and the A20, Rotterdam to Utrecht). This reflects the favoured locations of the firms in the APS sector. Many of these firms work for a national market. Central locations in the country along major transport arteries provide them with easy access to their market.

\section{CONCLUSION}

The maps clearly show disparate spatial realities of job access for different values of commuting tolerance. Large differences in job access have been found between the Randstad and the rest of the Netherlands, especially for high levels of commuting tolerance. Outside the Randstad, employment is concentrated in and close to the central cities and cities are located at relatively large distances from each other. This means that an increase in commuting tolerance does not lead to a rise in job access as spectacularly as in the Randstad. The first conclusion therefore is that urban form indeed has a tremendous impact on job access, at least at higher levels of commuting tolerance.

The polynucleated character of the Randstad has a very strong influence on individual job access. People who are willing to commute for 30 minutes, especially from suburban residential areas in between the larger cities, can reach many jobs. The short distances between the cities in the Randstad make it possible to see the whole Randstad as one daily urban system, or one functional labour market for those willing to commute for 45 minutes or more. However, this image is only a reality for a small proportion of the working population.

For a large part of the working population a commuting tolerance of 15 minutes is more realistic. At 15 minutes the map shows islands of job access directly surrounding the main cities. This confirms the findings of Cortie et al. (1992), who state that the Randstad should not be viewed as an integrated region, but as a collection of separate urban centres which function as separate socio-spatial systems. This conclusion is particularly valid for low-skilled workers. In general terms they can only enter up to $40 \%$ of all job opportunities on the basis of their limited skills. Given a commuting tolerance of less than 15 minutes, the residential areas in the traditional cities still offer maximum job access for these groups.

What can be learned from this exercise? Differences in residential location, commuting tolerance and human capital result in completely different images of job access. In order to develop efficient spatial policy with regard to job access, it is important to take into consideration the residential location and commuting tolerance of different socio-economic groups. The deconcentration of low-skilled employment from the central cities is certainly to the detriment of the low-skilled workers living in inner-city neighbourhoods. Commuting to suburban locations simply takes too much time; the spatial barriers are too great. Concentration of employment in the cities is an effective strategy. However, improving the commuting tolerance of those with low skills would have an even greater effect, since it has been shown that the effects of commuting tolerance clearly outweigh the effects of the geographical distribution of job opportunities.

At first sight job access for highly skilled workers seems to be much greater because of their greater commuting tolerance. However, particularly for those with highly sector specific human capital, the number of potential job opportunities is limited as the case of advanced producer services 
exemplifies. Since these job opportunities are dispersed over various cities in the Randstad and the rest of the country, high commuting tolerance seems to be a necessary condition for changing jobs without having to change residence. Further specialization of parts of the Randstad might help to arrive at a higher concentration of this sort of employment.

Most of the dual-earner households in the Netherlands consist of one full-time and one part-time worker. For them, residential locations along the ring roads of the major cities are superior, because they combine the best access to jobs at both 15 minutes and 30 minutes commuting tolerance. The present policies of both residential development (on the outer side) and urban regeneration (on the inner side) provides them with good quality housing opportunities at the best locations in terms of job access. Continuation of these policies should therefore be favoured.

\section{Notes}

1. The LISA data sets were made available by the Ministry of Housing, Spatial Planning and the Environment who commissioned the empirical application of the research.

2. The basisnetwerk was purchased from Traffic and Transport Consultancy Group (Adviesgroep voor Verkeer en Vervoer, Nieuwegein) in 1989 and updated to the present day at the Faculty of Geographical Sciences of Utrecht University.

\section{ACKNOWLEDGEMENTS}

Maarten van Ham's research was supported by the Netherlands Organization for Scientific Research (grant nr.42513002). Clara Mulder's research was made possible by a fellowship from the Royal Netherlands Academy of Arts and Sciences. The authors express their gratitude to Tom de Jong of the Urban Research centre Utrecht (URU), Faculty of Geographical Sciences, Utrecht University, for his help with the use of FLOWMAP to calculate the proximity counts used in this article. The authors further express their gratitude to Statistics Netherlands for the opportunity to analyse the Labour Force Surveys on-site (according to the WSA-CBS agreement).

\section{REFERENCES}

Alonso, W. (1964), Location and land use. Newbury Park, CA: Sage.

ATZEMA, O. \& V. SCHUTJENS (1995), Gebrek aan werk: regionale variaties. In: W. VAN DER VELDEN \& E. WEVER, eds., Nederland is meer dan de Randstad: de economische emancipatie van overig Nederland. pp. 105-127. Utrecht: Rabobank.

BATENBURG, R.S. \& M.C. DE WITTE (1996), Functiestructuur, verdringing en automatisering; regionale verschillen binnen Nederland. In: O. ATZEMA \& J. VAN DIJK, eds., Technologie en de regionale arbeidsmarkt. pp. 117-131. Assen: Van Gorcum.

BATTEN, D.F. (1995), Network cities: creative urban agglomerations for the 21st century. Urban Studies 32, pp. 313-327.

BECKER, G. (1962), Human capital: a theoretical and empirical analysis. Journal of Political Economy 70, pp. 9-46.

BÖRSCH-SUPAN, A. (1990), Education and its double-edged impact on mobility. Economics of Education review 9, pp. 39-53.

BURKE, G.L. (1956), The making of Dutch towns, a study in urban development from the tenth to the seventeenth centuries. London: Cleaver-Hume Press.

CentraAl Bureau VOOR DE STATISTIEK (CBS) (1997), Enquête Beroepsbevolking 1996 (Labour Force Survey, 1996). 'sGravenhage: Sdu.

ClARK, W.A.V. \& M. KUIJPERS-LindE (1994), Commuting in restructuring urban regions. Urban Studies 31, pp. 465-483. 
Cortie, C., M. DiJst \& W. Ostendorf (1992), The Randstad a metropolis? Tijdschrift voor Economische en Sociale Geografie 83, pp. 278-288.

DE JONG, T. \& H. FlOOR (1993), Flowmap: een programma voor het weergeven en analyseren van interactiegegevens (Flowmap: a software package for displaying and analysing interaction data). Planning, methodiek en toepassing 44, pp. 16-31.

DiEleman, F.M. \& A. FALUdi (1998), Randstad, Rhine-Ruhr and Flemish diamond as one polynucleated macroregion? Tijdschrift voor Economische en Sociale Geografie 89, pp. 320327.

FISHER, M.M. \& P. NiJKAMP (1987), Spatial labour market analysis: relevance and scope. In: M.M. FISHER \& P. NIJKAMP, eds., Regional Labour Markets. Amsterdam: North Holland.

GORDON, P., A. KUMAR \& H.W. RICHARDSON (1989), Gender differences in metropolitan travel behaviour. Regional Studies 23, pp. 499-510.

HALL, P. (1966), The world cities. 3rd edition 1984. London: Weidenfeld and Nicolson.

HANSON, S. \& G. PRATT (1992), Dynamic dependencies: a geographic investigation of local labor markets. Economic Geography 68, pp. 373-405.

HÄGERSTRAND, T. (1970), What about people in regional science? Papers of the Regional Science Association 24, pp. 7-21.

HeSSELS, M. (1992), Locational dynamics of business services, an intrametropolitan study of the Randstad Holland (Ph.D. thesis, University of Utrecht: Netherlands Geographical Studies, 147).

Holzer, H., IHLANFELD, K. \& SJOQUiST, D. (1994), Work, search and travel among white and black youth. Journal of Urban Economics 35, pp. 320-345.

HOOIMEIJER, P. (1996), A life-course approach to urban dynamics: state of the art in and research design for the Netherlands. In: G.P. CLARKE, ed. Microsimulation for urban and regional policy analysis. pp. 28-63. London: Pion.

JARVIS, H. (1999), Identifying the relative mobility prospects of a variety of household employment structures, 1981 - 1991. Environment and Planning A 31, pp. 1031-1046.

LOUTER, P.J. (1997), Regionale data voor beleidsdoeleinden. In: W. DE GRAAFF \& F. BOEKEMA, eds., Regionale data: vraag, aanbod en toepassing. pp. 5-26. Assen: Van Gorcum.

MADDEN, J.F. (1981), Why women work closer to home. Urban Studies 18, pp. 181-194.

MADDEN, J.F. \& WHITE, M.J. (1980), Spatial implications of increases in the female labour force: a theoretical and empirical synthesis. Land Economics 56, pp. 432-446.

MuldeR, C.H. (1993), Migration dynamics: a life course approach (Ph.D. thesis, University of Amsterdam: Thesis Publishers).

MUlDER, C.H. \& HoOIMEIJER, P. (1999), Residential relocations in the life course. In: L.J.G. VAN WISSEN \& P.A. DYKSTRA, EDS., Population Issues. An interdisciplinary focus, pp. 159-186. New York: Kluwer Academic/Plenum Publishers.

PHELPS, E.S. (1970), Introduction: The new microeconomics in employment and inflation theory. In: E.S. PHELPS, ed. Microeconomic foundations of employment and inflation theory. pp. 1-26. New York: Norton.

PRESTON, V. \& MCLAFFERTY, S. (1999), Spatial mismatch research in the 1990s: progress and potential. Papers in Regional Science 78, pp. 387-402.

PRIEMUS, H. (1998), The Randstad and the central Netherlands urban ring: planners waver between two concepts. European Planning Studies 6, pp. 443-455.

SIMPSON, W. (1992), Urban structure and the labour market: worker mobility, commuting and underemployment in cities. Oxford: Clarendon Press.

TERMOTE, M. (1980), Migration and commuting: a theoretical framework. Laxenburg, Austria: IIASA.

TOPEL, R.H. \& WARD, M.P. (1992), Job mobility and the careers of young men. Quarterly Journal of Economics 107, pp. 439-479.

VAN DER LAAN, L. (1998), Changing urban systems: an empirical analysis at two spatial levels. Regional Studies 32, pp. 235-247. 
VAN DER LAAN, L., J. VogelZANG \& R. SCHALKE (1998), Commuting in multi-nodal urban systems: an empirical comparison of three alternative models. Tijdschrift voor Economische en Sociale Geografie 89, pp. 384-400.

VAN DER VEGT, C. \& W.J.J. MANSHANDEN (1996), Steden en stadsgewesten: economische ontwikkelingen 1970-2015, Den Haag: Sdu Uitgevers.

VAN OMMEREN, J. (1996), Commuting and relocation of jobs and residences. A search perspective (Ph.D. thesis, Vrije Universiteit Amsterdam: Thesis Publishers).

WACHS, M. \& TAYLOR, B.D. (1993), The changing commute: a case study of the jobs-housing relationship over time. Urban Studies 30, pp. 1711-1730. 
Figure 1

Map of the Netherlands

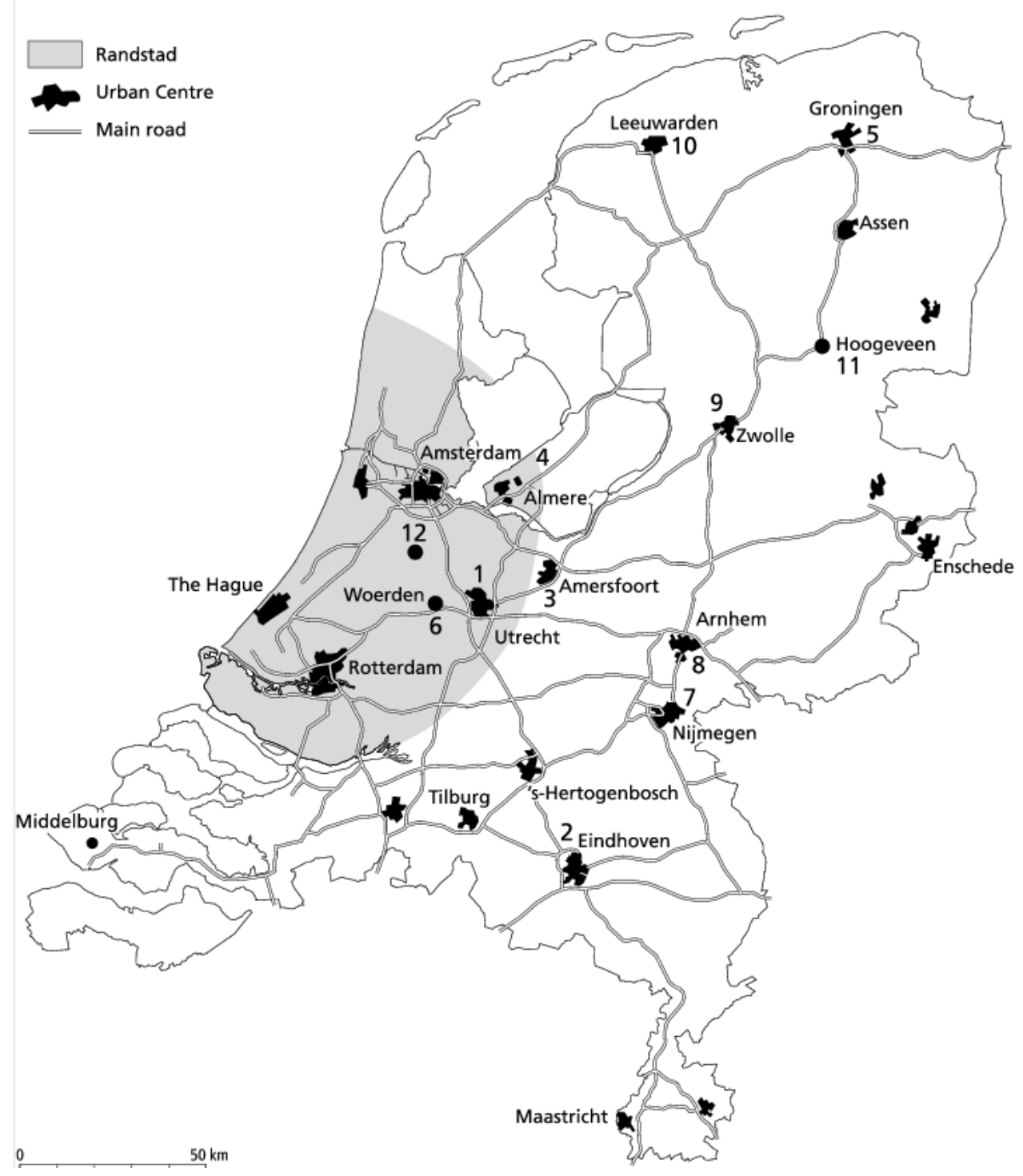


Figure 2 Jobs within reach, 15 minutes

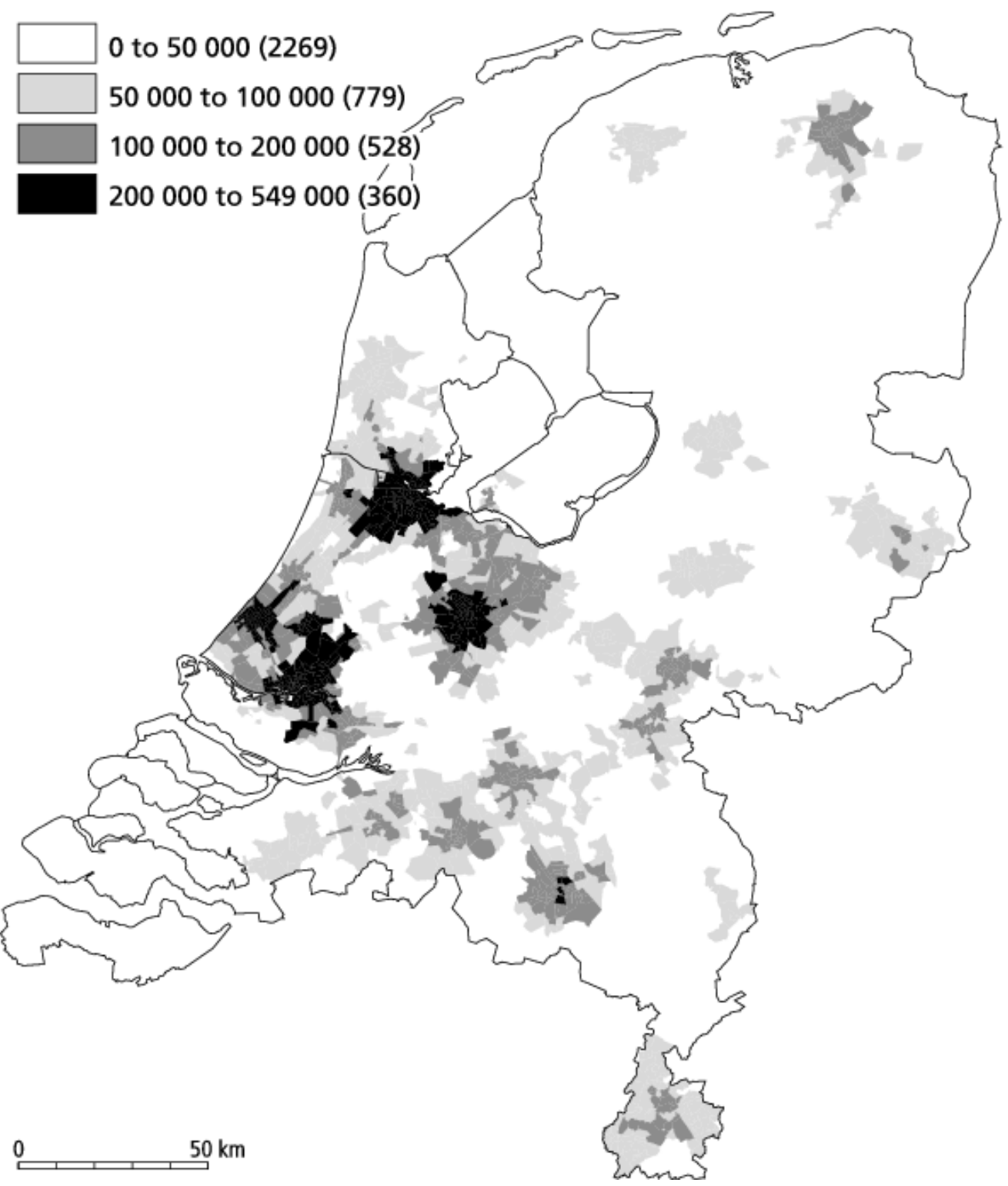

Source: LISA 1997 (in co-operation with VROM) 
Figure $3 \quad$ Jobs within reach, 30 minutes

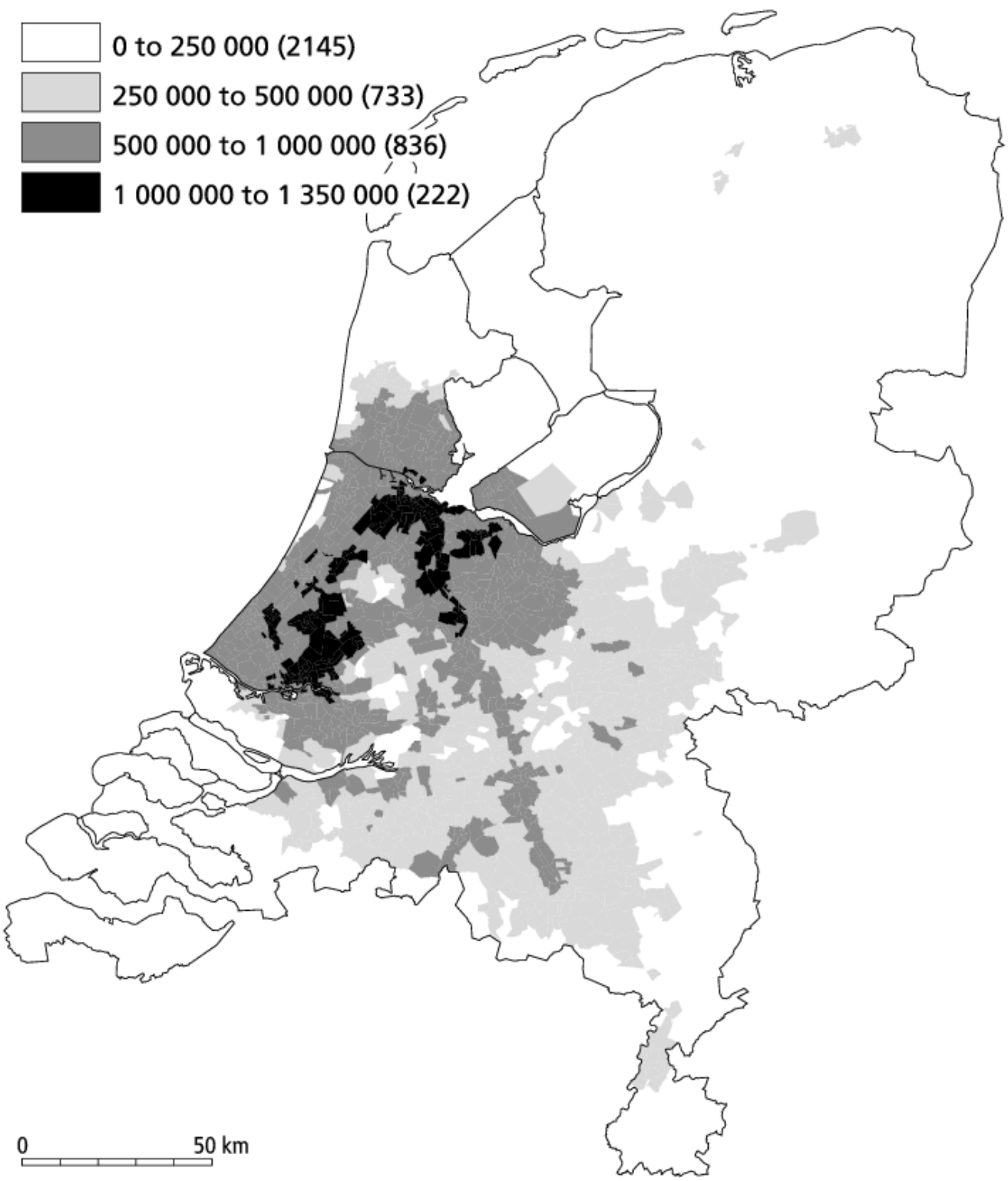

Source: LISA 1997 (in co-operation with VROM) 
Figure $4 \quad$ Jobs within reach, 30 minutes

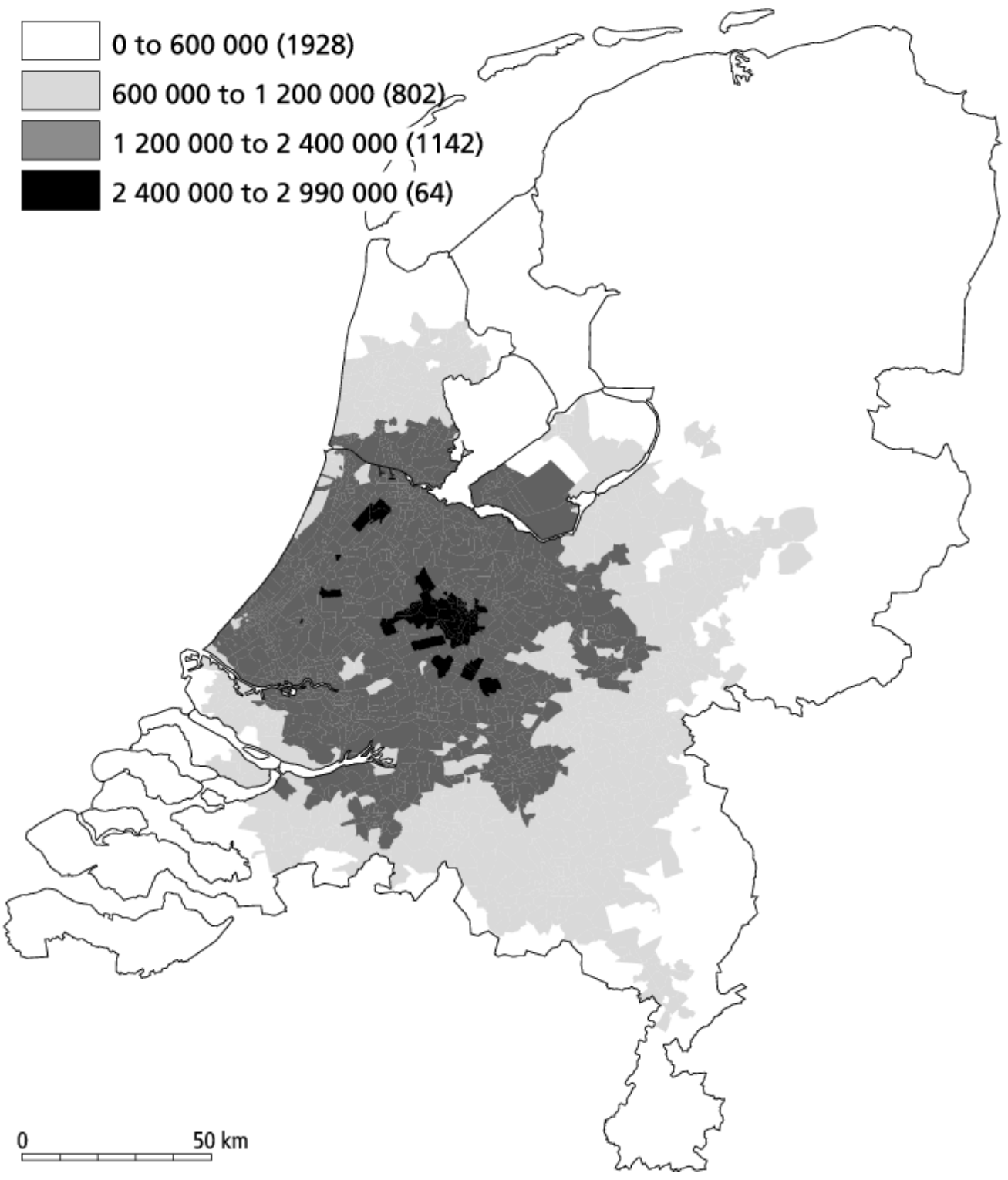

Source: LISA 1997 (in co-operation with VROM) 
Figure $5 \quad$ Basic and elementary jobs within reach of 15 minutes in the Randstad

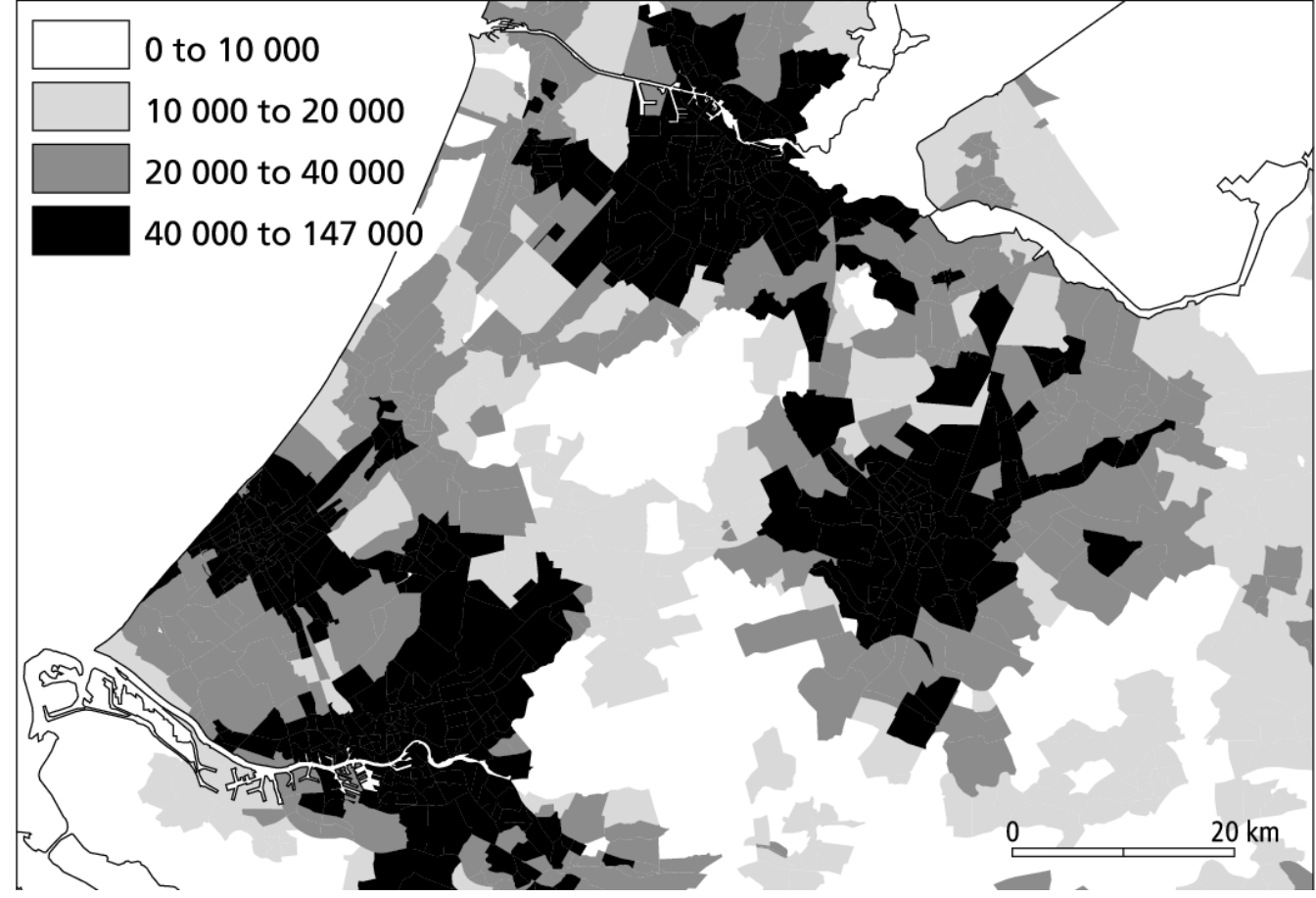

Source: LISA 1997, EBB 1994-1996

Figure $6 \quad$ Jobs within reach, 30 minutes: Advanced Producer Services

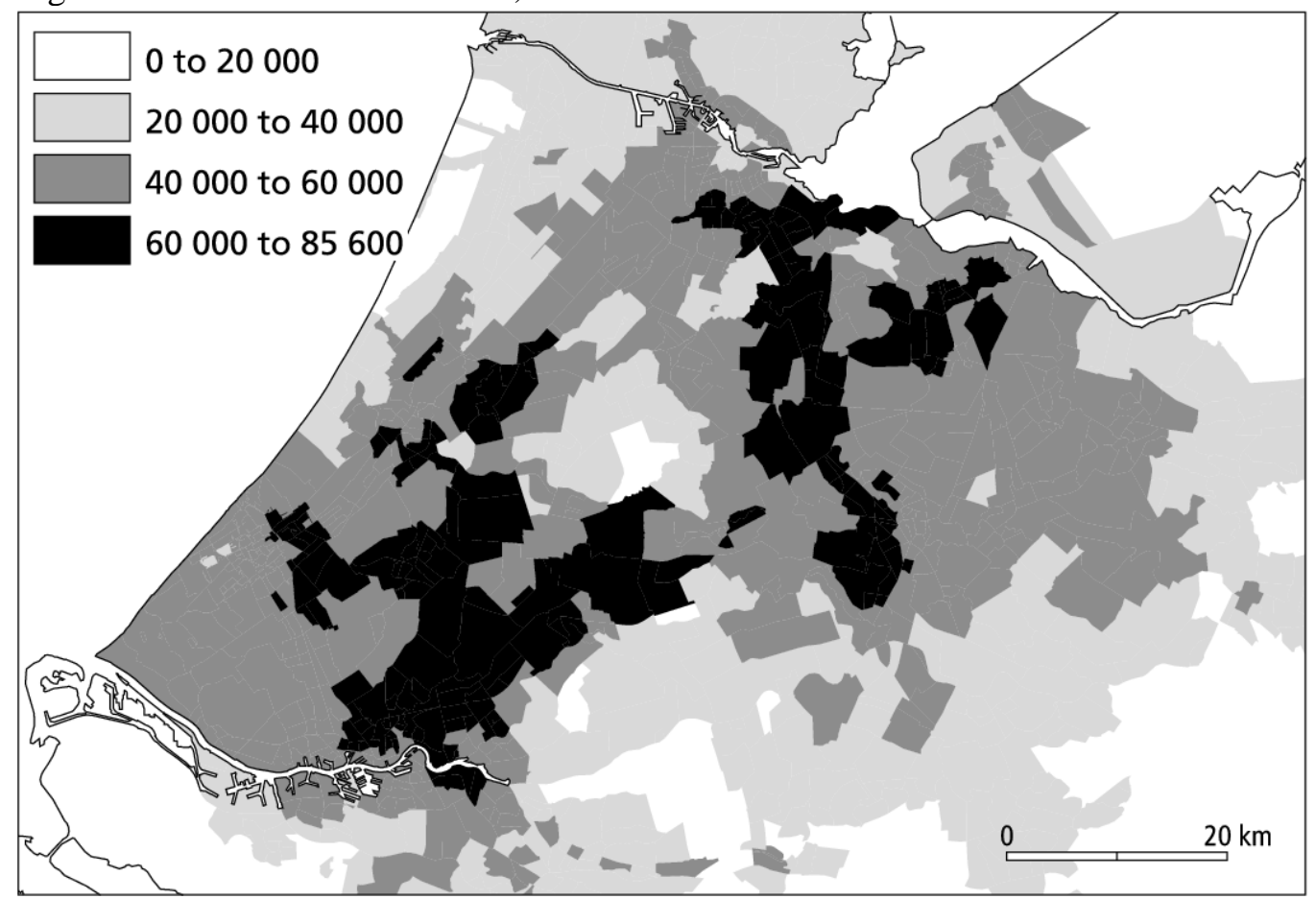

Source: LISA 1997 (in co-operation with VROM) 